\title{
Haematological Studies of Loranthus bengwensis Ethanolic Leaf Extract on Streptozotocin Induced Diabetic Rats
}

\author{
R.U. Ukpanukpong ${ }^{1 *}$, S.O. Oka ${ }^{2}$, O.E. Olarinde ${ }^{2}$, D.I. Basiru ${ }^{2}$, \\ B.E. Ukwuondi ${ }^{1}$ and P.O. Aigbadumah ${ }^{3}$ \\ ${ }^{I}$ Department of Biochemistry, Faculty of Basic Medical Sciences \\ University of Calabar, Nigeria \\ ${ }^{2}$ Department of Chemical Sciences, Joseph Ayo Babalola University, \\ Ikeji Arakeji. Osun State, Nigeria \\ ${ }^{3}$ Faculty of Medical Sciences, University of Jos, Nigeria \\ *Corresponding author
}

\section{Keywords \\ Phytochemicals, Body Weight, \\ Haemoglobin, \\ Packed Cell \\ Volume, Platelets, \\ White Blood Cell \\ and Red Blood Cell \\ Article Info \\ Accepted: \\ 15 February 2019 \\ Available Online: \\ 10 March 2019}

\section{A B S T R A C T}

The haematological studies on ethanolic leaf extract of Loranthus Bengwensis were evaluated in streptozotocin induced diabetics albino rats. The phytochemical screening of the ethanolic leaf extract showed the presence of alkaloids, flavonoids, steroids, tannin, saponins, cardiac glycosides, phenolics, terpenoid and quinines. Sixty albino wistar rats were used for the study and at the commencement of the experiment, rats were grouped into six study groups; Non-diabetic Control group, Diabetic Control group, Diabetic rats administered Orthodox drug insulin, Diabetic rats administered $100 \mathrm{mg}$ of leaf extract, Diabetic group administered with 200mg of leaf extract; Diabetic group administered with $400 \mathrm{mg}$ of leaf extract. There was a drastic reduction in blood glucose level of diabetes treated groups of DLB1, DBL2 and DBL3 at the end of the experiment which portrays the therapeutic efficacy of Loranthus bengwensis ethanolic leaf extract in ameliorating diabetic condition. However, the extract was more efficient at $400 \mathrm{mg} / \mathrm{kg}$ compared to $100 \mathrm{mg} / \mathrm{kg}$ and $200 \mathrm{mg} / / \mathrm{kg}$ respectively. This indicates that ethanolic leaf extract of Loranthus bengwensis is relatively more efficient at higher concentration. Other biochemical parameters such as; Haematological; Haemoglobin, Packed Cell Volume, WBC, Platelets Count and Neutrophiles as well as body weight indices were consideration. The results obtained from all these assays as well as the blood glucose assay justify the therapeutic efficacy of Loranthus bengwensis on diabetic condition.

\section{Introduction}

Plants are important source of biologically active substances; therefore they have been used for medicinal purposes, since ancient times. Plant materials are used as home remedies, in over-the-counter drug products, dietary supplements and as raw material for phytochemicals. The use of medicinal plants is usually based on traditional knowledge, from 
which their therapeutic properties are often ratified in pharmacological studies. Nowadays, a considerable amount of prescribed drug is still originated from botanical sources and they are associated with several pharmacological activities, such as morphine for analgesic, scopolamine and atropine as anticholinergics, galantamine associated with Alzheimer's disease, quinine as antimalarial, paclitaxel, vincristine and vinblastine all used as anticancer drugs, as well as digitalis glycosides used to alleviate heart failure. The versatility of biological actions can be attributed to the huge amount and wide variety of secondary metabolites in plant, belonging to several chemical classes as alkaloids, coumarins, flavonoids, tannins, terpenoids, xanthones, alkaloids, glycosides, volatile oils, minerals and vitamins etc (Canter et al., 2005).

However, world health organization consultative group define medicinal plants as any plant in which one or more of its constituents contain substances that can be used for therapeutic purposes and may serve as precursors for the synthesis of useful metabolites. The general belief about medicinal plant is that once a particular plant is used in the olden days and it worked for a particular ailment, people ignorantly start using it not minding the adverse effects. But, the advancement in medical science has really done a great work in that few medicinal plants pharmacokinetics is now known and some are synthetically processed as supplements (Sofowara, 1982). The high patronage for herbal drugs, in spite of the efficiency of synthetic drugs, is due to the misconception that natural products are not toxic, fewer side effects, with associated lower cost encourage this alternative therapy. In developing countries, herbal medicine is the main form of health care. Surprisingly, most herbal medicines do not have a defined dosage, inadequate information on the chemical composition and possible risks. Additionally, poor quality control measures on herbal drugs, may lead to adulteration and intrinsic factors related to used raw material, do produce variables and inconsistent effects.

Herbs are staging a comeback and herbal 'renaissance' is happening all over the globe. The herbal products today symbolize safety in contrast to the synthetics that are regarded as unsafe to human and environment. Although herbs had been priced for their medicinal, flavoring and aromatic qualities for centuries, the synthetic products of the modern age surpassed their importance, for a while. However, the blind dependence on synthetics is over and people are returning to the naturals with hope of safety and security. Over threequarters of the world population still relies mainly on plants and plant extracts for health care. More than $30 \%$ of the entire plant species, at one time or other is used for medicinal purposes (Odebiyi and Sofowora, 1978).

In spite of the overwhelming influences and our dependence on modern medicine and tremendous advances in synthetic drugs, a large segment of the world population still likes drugs from plants. In many of the developing countries the use of plant drugs is increasing because modern life saving drugs are beyond the reach of three quarters of the third world's population although many such countries spend $40-50 \%$ of their total wealth on drugs and health care. As a part of the strategy to reduce the financial burden on developing countries, it is obvious that herbal medicine will be highly encouraged in the future.

\section{Materials and Methods}

\section{Chemicals}

Streptozotocin, chloroform, ethanol and other chemicals were obtained from Fam-lab Nigeria Limited and Lixok-k chemicals, 
Akure. Alanine transaminases (ALT), Aspartate transaminase (AST), Serum albumin were obtained from Randox Laboratories Limited, UK. Accu-check glucometer kit was purchased from De-shalom pharmacy, Ilesa, Osun State, Nigeria. All other chemicals used were of analytical grade. De-ionised and distilled water was also used during the experimental process.

\section{Source of standard drug}

Insulin injection $(40 \mathrm{I} / \mathrm{ml})$ marketed by May and Baker, was obtained from a registered pharmacist in De-shalom pharmacy, Ilesa, Osun State, Nigeria and used for the study.

\section{Experimental animals}

Adult sixty (60) female albino rats weighing between 90-250g were purchased from a disease free stock of the University of Ibadan, Nigeria and used for the study. The rats were randomly assigned on the basis of their weight into six study groups of eight (8) rats each. Normal feeds and tap water were given to the rats ad-libitum while food and water intake were noted. They were kept in plastic cages of 8 rats per cage, placed in a well ventilated animal house of Joseph Ayo Babalola University at normal temperature of $30-35^{\circ} \mathrm{C}$. The cages were cleaned daily and rats were treated according to the international guidelines for the care and use of laboratory animals (NIH, 2008). The animals were allowed for two weeks of acclimatization and their weights were measured before treatment commenced.

\section{Plant materials and identification}

Fresh leaves of Loranthus bengwensis were obtained from kolanut tree in Ikeji-Arakeji plantation, Osun State, Nigeria. The plant samples were taken to the Department of Botany, Obafemi Awolowo University (O.A.U) for identification and authentication.

\section{Preparation of plant extracts}

Loranthus bengwensis leaves were sorted out washed to remove dirts and dust particles and air dried under shade for 4 weeks. The dried materials were homogenized using mechanical grinder and weighed in a weighing balance. The powder form was kept in airtight container and stored at $4^{\circ} \mathrm{C}$ until when needed for further analysis.

\section{Extraction procedures}

$150 \mathrm{~g}$ of the powdered extract was soaked in $98 \%$ of ethanol in $250 \mathrm{ml}$ at room temperature for 72 hours after which the mixture was filtered. The filtrate was placed in centrifuge at $540 \mathrm{rev} / \mathrm{min}$ for 30 minutes. The centrifuged sample formed 2 layers; the upper layer was then poured inside another beaker. It was boiled at $60^{\circ} \mathrm{C}$ using a water bath. During the boiling process, it was observed that the sample formed a crystal structure in a foaming form. The resulting filtrate was air-dried at room temperature into petri dishes. The residue obtained was weighed and kept in airtight container at $4^{\circ} \mathrm{C}$. Percentage yield was determined from the weight of the dried sample.

\section{Phytochemical screening}

Basic phytochemical screening was the method employed to test the presence of certain biologically active compounds in plants e.g. tannins, saponins, antraquinone, flavonoids, cardiac glycosides, steroids, phenolics, cardenolides and denolides.

\section{Induction of diabetes}

Diabetes mellitus was induced by single intraperitoneal dose of $60 \mathrm{mg} / \mathrm{kg}$ of streptozotocin (Sigma chemicals, St Louis USA) dissolved in $0.1 \mathrm{M}$ fresh cold citrate buffer at a $\mathrm{pH}$ of 4.5 into 12 hours overnight fasted rats (Burcelin et al., 1995). After 3 
days, fasting blood sugar levels were monitored with a glucometer (Accu check active, Roche Diagnostics GmbH, Germany) and the rats having fasting blood glucose levels more than $200 \mathrm{mg} / \mathrm{dl}$ were isolated, classified diabetic and used for experimentation.

\section{Experimental design}

The grouping and treatment given to the rats in each groups are as follows; Group A: Designated as NDC consisted of non-diabetic control rats administered $1 \mathrm{ml}$ of distilled water. Group B: Designated as DC consisted of diabetic control rats administered $1 \mathrm{ml}$ of streptozotocin. Group C: Designated as DO consisted of diabetic rats administered $1 \mathrm{ml}$ of orthodox drug (insulin). Group D: Designated as DLB1 consisted of diabetic rats administered $100 \mathrm{mg} / \mathrm{kg}$ of Loranthus bengwensis ethanolic leaf extract. Group E: Designated as DLB2 consisted of diabetic rats administered $200 \mathrm{mg} / \mathrm{kg}$ of Loranthus bengwensis ethanolic leaf extract. Group F: Designated as DLB3 consisted of diabetic rats administered $400 \mathrm{mg} / \mathrm{kg}$ of Loranthus bengwensis ethanolic leaf extract.

\section{Determination of haematological parameters}

\section{Packed cell volume}

Method: Micro haematocrit (Baker and Silverton, 2003)

Materials: Capillary tube, Haematocrit centrifuge, Haematocrit reader, Plasticine.

Principle: Anticoagulant blood in a glass capillary of specified length, bore size and wall thickness is centrifuged at 12,000 rpm for 5 minutes to obtain a constant packing of the red blood cells while the plasma remains above the cells.
Procedure: The capillary tube was filled with the mixed blood up to $3 / 4$ of its length, one of the ends of the capillary was sealed with plasticine. It was placed in the centrifuge and spun for $5 \mathrm{mins}$ at $12,000 \mathrm{rpm}$. It was then read on the hematocrit reader.

Total white blood cell count: This was determined using bulk dilution method of Ochei and Kolhatkar (2007).

\section{Differential white cell count}

Haemoglobin estimation: Haemoglobin was determined using the method of (Baker and Silverton, 2003).

\section{Mean corpuscular hemoglobin concentration}

Principle: The mean corpuscular hemoglobin concentration is a measure of the concentration of hemoglobin in a given volume of packed cell blood cells. It is reported as part of standard complete blood count.

Method: It was calculated by dividing the hemoglobin by the hematocrit. Reference ranges for blood tests are 32 to $36 \mathrm{~g} / \mathrm{dl}$, or between 19.9 and $22.3 \mathrm{mmol} / \mathrm{l}$.

Sacrifice of the animals and serum collection: At the end of the experimental period, rats in each study group were fasted overnight and sacrificed under anesthesia by cervical dislocation. After the rats have been sacrificed, $2-4 \mathrm{ml}$ of blood was collected from each rat and placed in specific sterile bottles (plain bottles for enzyme analysis and EDTA bottles for haematological indices). For enzyme analysis, the blood was allowed to stand for 30 minutes to clot and then centrifuge at $4000 \mathrm{~g}$ for 15 minutes. The supernatant, which is the serum, was carefully decanted and was kept at $4^{\circ} \mathrm{C}$ for further analysis. 
Statistical analysis: The data will be expressed as Mean value \pm S.E.M (Standard error of the mean). All results will be mean of 8 data samples and the statistical analysis will be carried out using student's t-test. The values will be considered at probability level of $\mathrm{P}<0.05$.

\section{Results and Discussion}

Herbal medicine have recently drawn much attention as an alternative medicine useful for treatment and prevention of lifestyle related disorders but there is inadequate knowledge on the pharmacokinetics of medicinal plants. There is a growing interest in the analysis of plant products which has stimulated intense research on their potential health benefits (Viswanath et al., 2007). There are about 200 pure compounds from plant sources reported to show hypoglycemic effect. The compounds include alkaloids, carbohydrates, amino acids, lipids, flavonoids, steroids, terpenoids, glycosides, glycopeptides, phenolics as well as many other phytochemical constituents (Table 1). More than 1200 species of plant have been screened for activity on the basis of ethanomedicinal uses (Dewanjee et al., 2009).

The phytochemical analysis of the ethanolic leaf extract of Loranthus bengwensis contains important phytoconstituents such as alkaloids, flavonoids, steroids, tannins, saponins, cardiac glycosides, phenolics, terpenoids and quinones while anthraquinones, cardenolides and denolides and oxalates and are absent. Flavonoids and tannins have been reported to cause regeneration of damaged pancreatic islets, stimulate calcium and glucose uptake (Tapas et al., 2008). These compounds are also known to be responsible for the hypoglycemic activity of Loranthus bengwensis as compared with other hypoglycemic plants which contains similar phytoconstituents as found in Luffa acutangula fruit extract (Pimple et al., 2011) and methanolic root bark extract of Acacia albida (Salisu et al., 2009). These findings are in agreement with Olatunde and Dikwa (2014) who carried out an experiment on the qualitative and quantitative analysis of phytochemicals in Loranthus bengwensis leaf and had similar findings.

The body weight indices of the experimental groups, at the commencement of the experiment compared to its weight at the end of the experiment demonstrated a significant increase (Fig. 1). This can be attributed to the administration of ethanolic extract of Loranthus bengwensis which can hence be said to cause an increase in body weight. This increase was however more significant ( $\mathrm{p}<$ $0.05)$ in the ethanolic extract treated groups (Group D, E and F) than in the standard drug treated group (Group C). This is in contrast with a research carried out by Mojekwu et al., (2011) who used Aframomum melegueta to ameliorate the diabetic condition in the experimental rats and discovered a decrease in body weight at varying concentrations of the aqueous leaf extract of Aframomum melegueta.

The haematological results shows that administration of ethanolic leaf extract of Loranthus bengwensis had increasing effects on all haematological parameters at all concentrations of the extract (Fig. 2). This shows that the extract has the ability to increase blood volume and hence constituting haematological components. Compared to the positive control group, there was an insignificant increase in the WBC count of the rats in the extract treated groups (Group D, E and $\mathrm{F}$ ) at $\mathrm{P}<0.05$. This shows the activity of the WBC count in fighting the preceding diabetic condition serving as the second line of immunological defense. The white blood cell count however began to decrease significantly (at $\mathrm{P}<0.05$ ) as the extract began to ameliorate the diabetic condition as 
observed when compared to the negative control group. Also, a decrease was observed in orthodox treated group (Group C) when compared to the negative control group. This decrease was however statistically insignificant at $\mathrm{P}<0.05$.

The Packed Cell Volume (PCV) is a fraction of the whole blood volume that consists of red blood cells. The PCV is on the increase in all treated groups (Group C, D, E and F) compared to the non-diabetic control group. This increase is however statistically insignificant at $\mathrm{P}<0.05$. A significant increase was observed in all treated groups when compared to the negative control group. Hemoglobin is one-third of the packed cell volume and is responsible for oxygen transport in the blood. There was a significant increase in the groups treated with ethanolic leaf extract of Loranthus bengwensis as compared to the negative control group and positive control group. Platelets are involved in blood clotting and are a major component of the blood. There was a significant increase in platelet count in all ethanolic leaf extract treated groups when compared to the negative control due to the ability of the plant extract to increase total blood volume and hence its constituting components. But there was an insignificant decrease in the platelets count of all treated groups when compared to the nondiabetic control group (Fig. 3 and 4).

Table.1 Phytochemical screening of ethanolic leaf extract of Loranthus bengwensis

\begin{tabular}{|l|l|c|}
\hline S/N & Phytochemicals & Inference \\
\hline $\mathbf{1}$ & Alkaloids & + \\
\hline $\mathbf{2}$ & Flavonoids & + \\
\hline $\mathbf{3}$ & Cardiac glycosides & + \\
\hline $\mathbf{4}$ & Steroids & + \\
\hline $\mathbf{5}$ & Saponins & + \\
\hline $\mathbf{6}$ & Tannins & + \\
\hline $\mathbf{7}$ & Anthraquinones & + \\
\hline $\mathbf{8}$ & Phenolics & + \\
\hline $\mathbf{9}$ & Terpenoids & + \\
\hline $\mathbf{1 0}$ & Quinones & - \\
\hline $\mathbf{1 1}$ & Oxalates & - \\
\hline $\mathbf{1 2}$ & Cardenolides and Denolides \\
\hline \multicolumn{2}{|c|}{ + indicates the presence of the phytochemical } \\
\multicolumn{2}{|l|}{} & - indicates the absence of the phytochemical. \\
\hline
\end{tabular}

Fig.1 Body weight indices of experimental rats.

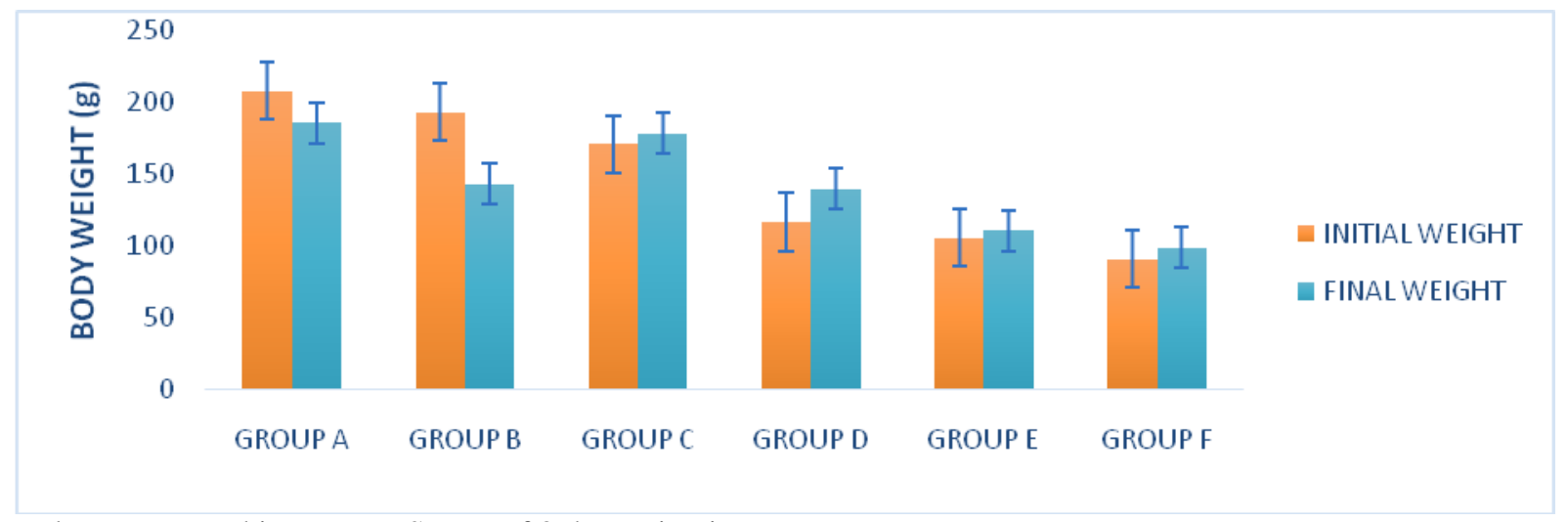

Values expressed in Mean \pm S.E.M of 8 determinations 
Fig.2 Haemoglobin, Pack cell volume and Neutrophils levels of experimental rats

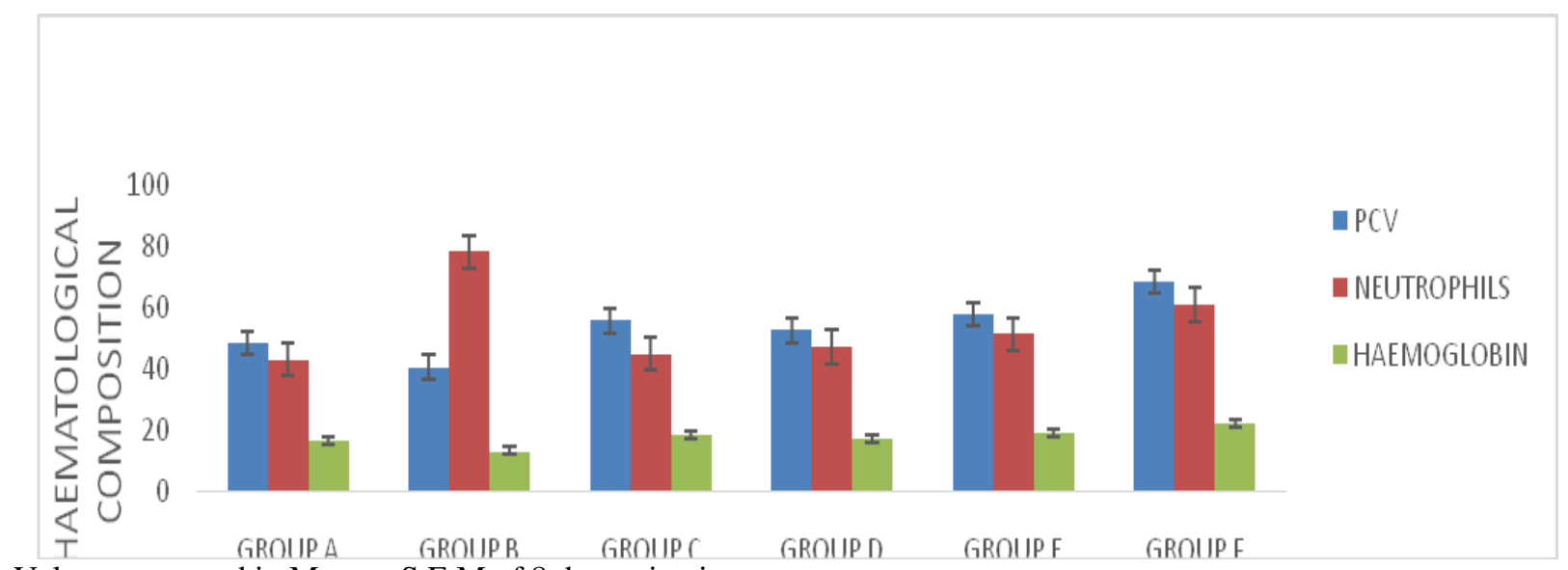

Values expressed in Mean \pm S.E.M of 8 determinations

Fig.3 White blood cell count of experimental rats

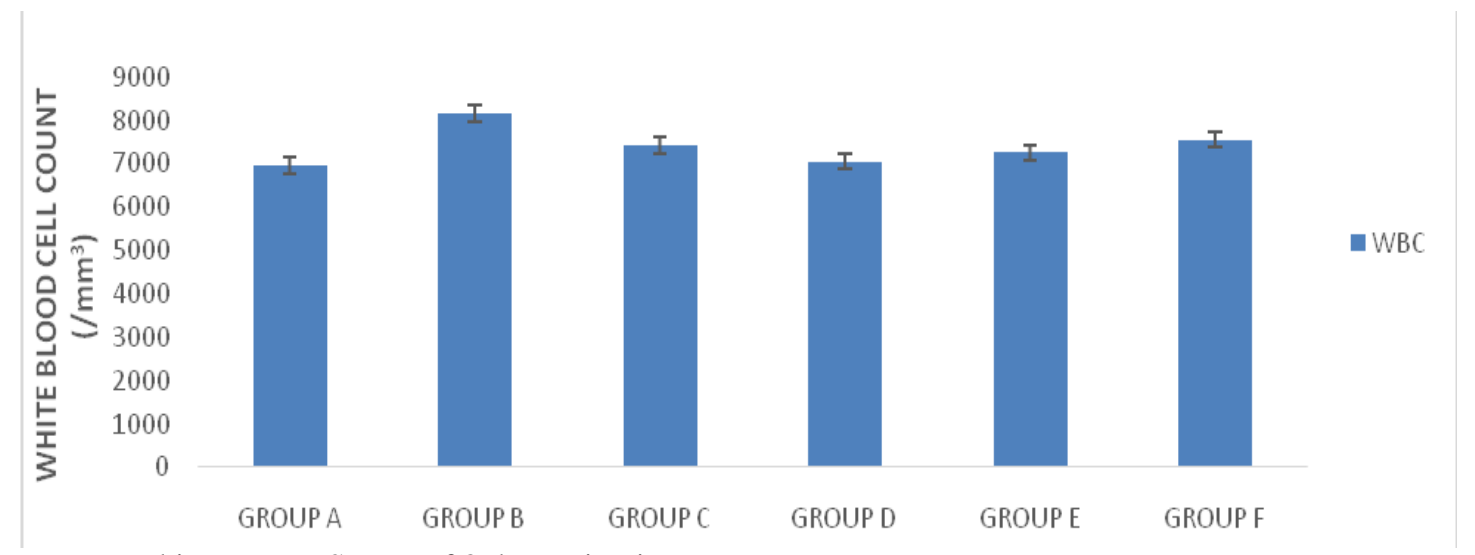

Values expressed in Mean \pm S.E.M of 8 determinations

Fig.4 Platelets count of the experimental rats

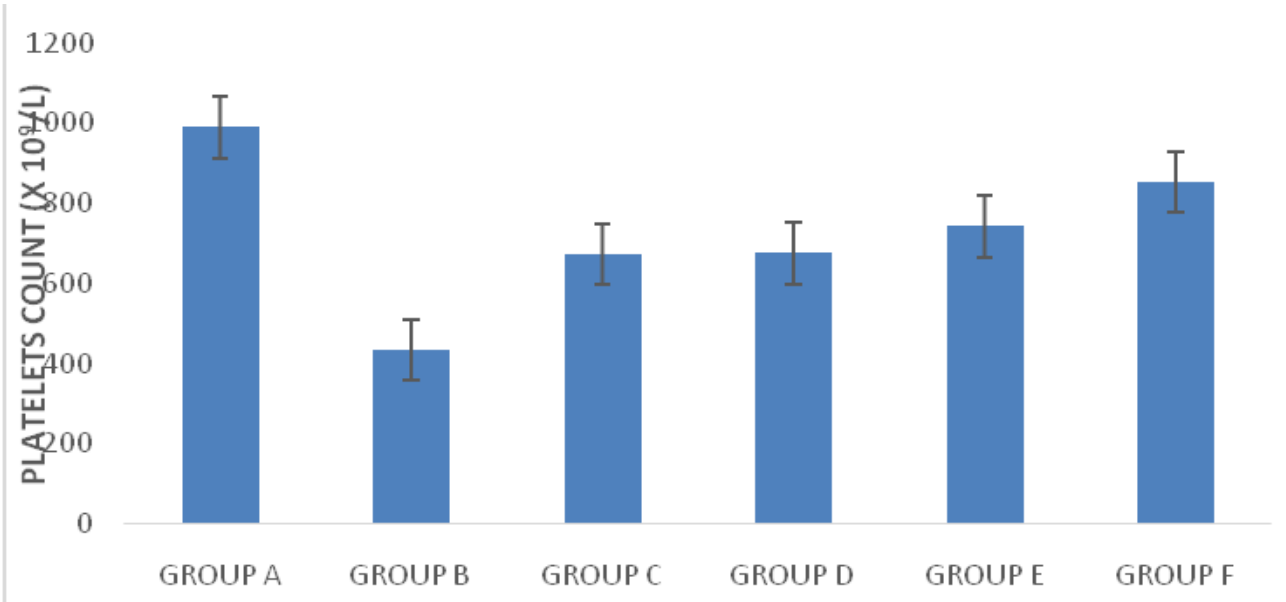

- PLATELETS

Values expressed in Mean \pm S.E.M of 8 determinations 
Neutrophils are the most abundant type of white blood cells in the blood. They are essential in destruction and removal of some species of bacteria, wastes, foreign substances with the sole purpose of protecting the body. A decrease was observed in the neutrophils count of groups treated with ethanolic leaf extract of Loranthus bengwensis when compared to the negative control (Group B) because of the ability of the leaf extract to ameliorate the diabetic condition and therefore, initiate a reduction in the production of white blood cells and hence, neutrophils. This decrease was however statistically insignificant at $\mathrm{P}<0.05$. An increase was however observed in these treated groups when compared to the positive control group due to the pre-diabetic condition of the rats. A decrease compared to the negative control group (Group B) was also observed in the orthodox treated group (Group C), this decrease was however less significant compared to the groups treated with ethanolic leaf extract of Loranthus bengwensis.

Urea which is an important metabolite in the urine and also a major nitrogen containing compound in urine. It plays a role as a major carrier of nitrogen. There was a statistically non significant decrease $(\mathrm{P}<0.05)$ in the urea levels of the extract treated groups, D, E and $\mathrm{F}$ compared to the negative control group. This may be due to the ability of the plant extract to reduce urea levels in the blood serum of the rats, at varying concentrations, maybe by facilitating their excretion through the urine.

\section{References}

A.O.A.C. (2001). Official methods of analysis, $16^{\text {th }}$ edition. Association of Official Analytical Chemist, Arlington, V.A. Pp 267

Baker, R and Silverton, T. (2003). Blood:
Principles \& Practice of Hematology. Lippincott Williams \& Wilkins Jounr. 89(6):78-82

Canter, B.C., Robert, J., Philip, M., and Guyton, F.K. (2005). Pharmacological actions of Abies pindrow Royle leaf. Indian Jour. Expt. Biol; 36:187-191.

Dewanjee, S., Das, A.K., Sahu, Ri and Gangopadhyay, M. (2009). Antidiabetic activity of Diospyrous peregina fruit: effect on hyperglycemia, hyperlipidemia and augumented oxidative stress in experimental type 2 diabetes. Food Chem. Toxicol., 47:2679-2685.

Mojekwu T.O., Yama O. E., Ojokuku S.A. and Oyebadejo S.A. (2011). Hypoglycemic Effects of Aqueous Extract of Aframomum melegueta Leaf on Alloxan-Induced Diabetic Male Albino Rats. Pac J. Med Sci: 8(1):356378

Ochei, R. and Kolhatkar, J. (2007). "Invivonear-Infrared spectroscopy". Annual Review of Biomedical Engineering 6(2): 715-754.

Odebiyi, A., and Sofowora, A.E. (1978). Phytochemical screening of Nigeria Medicinal Plants (Part III). Lioydia 41: $234-246$.

Olatunde Ahmed and Dikwa Mohammad Ali (2014). Qualitative and quantitative analysis of phytochemicals in Loranthus bengwensis leaf. Int RJ Pharm. Sci. 5(1):10-12.

Pimple P, Kadam V, Patil J (2011). Antidiabetic and antihyperlipidemic activity of Luffa actungula fruit extracts in streptozotocin induced Niddm rats. Asian J. Pharm. Clin. Res. 4(2):156163.

Proctor, P. (1970). Similar functions of uric acid and ascorbate in man. Nature. 228 (5): 868 .

Reitman FJ and Frankel ET (1957). "Purification and characterization of 
aspartate aminotransferase from the halophile archaebacterium Haloferax mediterranei". Biochem Journ 278 (1): 149-154.

Salisu Y, Abubakar M, Ibrahim G (2009). Hypoglycemic effects of Acacia albida methanolic root bark extract. Niger. J. Pharm. Sci. 8(1):66-72.

Sofowara A, (1982). Medicinal Plants and Traditional medicine in Africa. Asian Pac. J. Trop. Med. 21(6): 427-433.

Tapas A, Sakarkar D, Kakde R (2008). Flavonoids as Nutraceuticals: A review.
Trop. J. Pharm. Res. 7:1089-1099. Viswanath G.L., Srinath R, Nandakumar K, Shylaja H and Lakshman K. (2007). Antidiarrheal activity of alcoholic and aqueous extracts of stem bark of Thespesia populnea in rodents. Pharmacologyonline; 3(1) 222-230.

Wright A and Plummer C (1974). "A finestructure genetic and chemical study of the enzyme alkaline phosphatase of $\mathrm{E}$. coli. I. Purification and characterization of alkaline phosphatase". Biochim. Biophys. Acta 38(4): 470-483.

\section{How to cite this article:}

Ukpanukpong, R.U., S.O. Oka, O.E. Olarinde, D.I. Basiru, B.E. Ukwuondi and Aigbadumah, P.O. 2019. Haematological Studies of Loranthus bengwensis Ethanolic Leaf Extract on Streptozotocin Induced Diabetic Rats. Int.J.Curr.Microbiol.App.Sci. 8(03): 1780-1788. doi: https://doi.org/10.20546/ijcmas.2019.803.208 